\title{
Oxidative Hydroxylation of Aryl Boronic Acid Catalyzed by Co-porphyrin Complexes via Blue-Light Irradiation
}

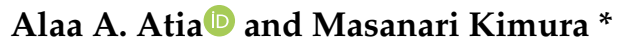 \\ Graduate School of Engineering, Nagasaki University, 1-14 Bunkyo-machi, Nagasaki 852-8521, Japan; \\ bb52218301@ms.nagasaki-u.ac.jp \\ * Correspondence: masanari@nagasaki-u.ac.jp; Tel.: +81-95-819-2677; Fax: +81-95-819-2677
}

Received: 30 September 2020; Accepted: 24 October 2020; Published: 30 October 2020

check for updates

\begin{abstract}
Oxidative reactions often require unstable and environmentally harmful oxidants; therefore, the investigation of safer alternatives is urgent. Here, the hydroxylation of aryl boronic acid in the presence of Co-complexes is demonstrated. Tetrakis(4-carboxyphenyl) Co(II)-porphyrin was combined with biodegradable polymers such as chitosan catalyzed hydroxylation of phenyl boronic acids to form phenol derivatives under blue-light irradiation. This catalytic system can be used as an eco-friendly oxidation process that does not release oxidizing agents into the atmosphere.
\end{abstract}

Keywords: aryl boronic acid; phenol; co-catalyst; porphyrin; photoredox; chitosan; polyaniline; hydroxylation; blue light; oxidation

\section{Introduction}

Oxidation reactions are abundant and necessary to form important useful intermediates in the laboratory, commonly by using unstable oxidants such as hydrogen peroxide [1], oxone [2], $\mathrm{NaClO}_{2}$ [3], $N$-oxide, mCPBA [4] and hypervalent iodine [5]. Methylene blue has also been used as a photosensitizer under aerobic conditions for oxidative hydroxylation [6-8]. Recently, there has been increased attention within the industry on eco-friendly oxidation processes and their development. In pursuit of this effort, new and advanced oxidation reactions that are safer, faster and more environmentally friendly have been developed [9]. For example, eco-friendly oxidation processes have been developed and used significantly in the field of modern organic synthesis [10]. Cozzi et al. studied the green methodology for hydroxylation of aryl boronic acid in open air using two equivalents of sodium ascorbate [11]. The combination of sodium ascorbate with atmospheric oxygen produced hydrogen peroxide, which was able to oxidize arylboronic acid [12,13].

The synthesis of phenols has received much attention in recent studies because of its importance as a starting material and structural constituent of pharmaceuticals, polymers, versatile intermediate building blocks [14] and natural products [15-17]. Mulakayala et al. reported the preparation of phenols from aryl boronic acids by treatment with hydrogen peroxide in the presence of Amberlite IR-120 resin; the reaction was conducted at room temperature in the absence of an organic solvent [18]. Under these conditions, catalytic hydroxylation in water promoted by complexes with recyclable ligands is highly desirable [19]. Alternatively, molecular or atmospheric oxygen can be used as an eco-friendly oxidant but poses a considerable challenge because of its relatively weak oxidation characteristics. Obtaining fast kinetics and high yields under these conditions requires an efficient catalytic system with complicated ligands, which requires a long time to complete the reactions [20]. $\mathrm{Co}$ (II)-porphyrin was chosen as a good catalyst because it has a higher ability to bind towards $\mathrm{O}_{2}$ in aqueous solution besides the stability and long-lifetime phosphorescence compared to $\mathrm{Cu}$ (II) that has a far shorter lifetime phosphorescence [21,22]. 
Metalloporphyrins are biomimetic catalysts that have gained popularity because of their distinctive catalytic activities coupled with environmental stability [23,24]. The development of metalloporphyrin as a good catalyst has been demonstrated in several synthetic transformations that are of great interest for oxidation, such as via $\mathrm{C}-\mathrm{H}$ activation of alkanes, epoxidation of alkenes and sulfoxidation of sulfides with oxygen molecules or under aerobic conditions possibly via radical-chain mechanisms $[25,26]$. In particular, immobilized porphyrins with bioavailable, nontoxic and antimicrobial polymers such as chitosan and polyaniline (PANI) have promising biomedical applications and demonstrated chemical stability [27]. Poltowicz et al. reported the increase of catalytic activity of Fe, $\mathrm{Mn}$ and Co porphyrins by supporting polyaniline as a catalyst in co-oxidation of styrene and isobutyraldehyde by gas phase oxygen [28]. The combination of polyaniline with porphyrin would further broaden its application range, especially in gas sensors, solid dye-sensitized solar cell (DSSC), powerful catalyst and fluorescence properties, as well as photocatalysis application [29-31]. Decreasing the environmental impact by immobilized metalloporphyrin on chitosan was a catalyst in the oxidation of ethylbenzene to produce less pollution reaction [32]. Chitosan, cheap and eco-friendly, was used to increase the catalytic activity of porphyrin [33].

Recently, it was reported that Co(II)-porphyrin catalysts effectively promoted oxidation of azo dye Orange II in the presence of hydrogen peroxide and led to mineralization in an aqueous solution [34]. Furthermore, Co(II)-porphyrin was so effective that it was used as a catalyst in the oxidation of azo dyes to water and carbon dioxide via hydroxyl radical active species [35].

Photoredox processes are also attractive as sustainable methods and have received much attention in the catalytic activation of organic molecules [36]. These methods depend on metal complexes with photosensitizers to engage in a single-electron transfer (SET) for photoexcitation processes under irradiation of visible light. Despite stoichiometric changes to the catalytic protocol, most of these reactions often have disadvantages such as intrinsic toxicity and energy consumption for the removal of the complexes [37] and require specific conditions such as the elimination of air, moisture and impurities [38]. The superoxide radical anion generated from the photoredox cycle can oxidize the arylboronic acid because of its Lewis acidity, which arises from the boron atom that has vacant $p$-orbital, the reaction proceeds promoted by $\left[\mathrm{Ru}(\mathrm{bpy})_{3} \mathrm{Cl}_{2}\right] \cdot 6 \mathrm{H}_{2} \mathrm{O}$ in the presence of TEA (trietyhlamine) under irradiation visible light [14].

Because they are one of the more efficient photocatalytic systems, use of porphyrins has also been developed in sustainable flow processes [34]. In this context, we developed oxidative reactions catalyzed by $\mathrm{Co}$ (II)-porphyrin under blue-light irradiation to form useful molecules. We reported a new method for the oxidative hydroxylation of aryl boronic acids to phenols in air, promoted by $\mathrm{Co}(\mathrm{II})$-porphyrins combined with biodegradable polymers as an eco-friendly catalyst (Scheme 1). We focused on Co(II)-porphyrins immobilized to chitosan or polyaniline because of the ease of synthesis and stability for photo-irradiation processes. 

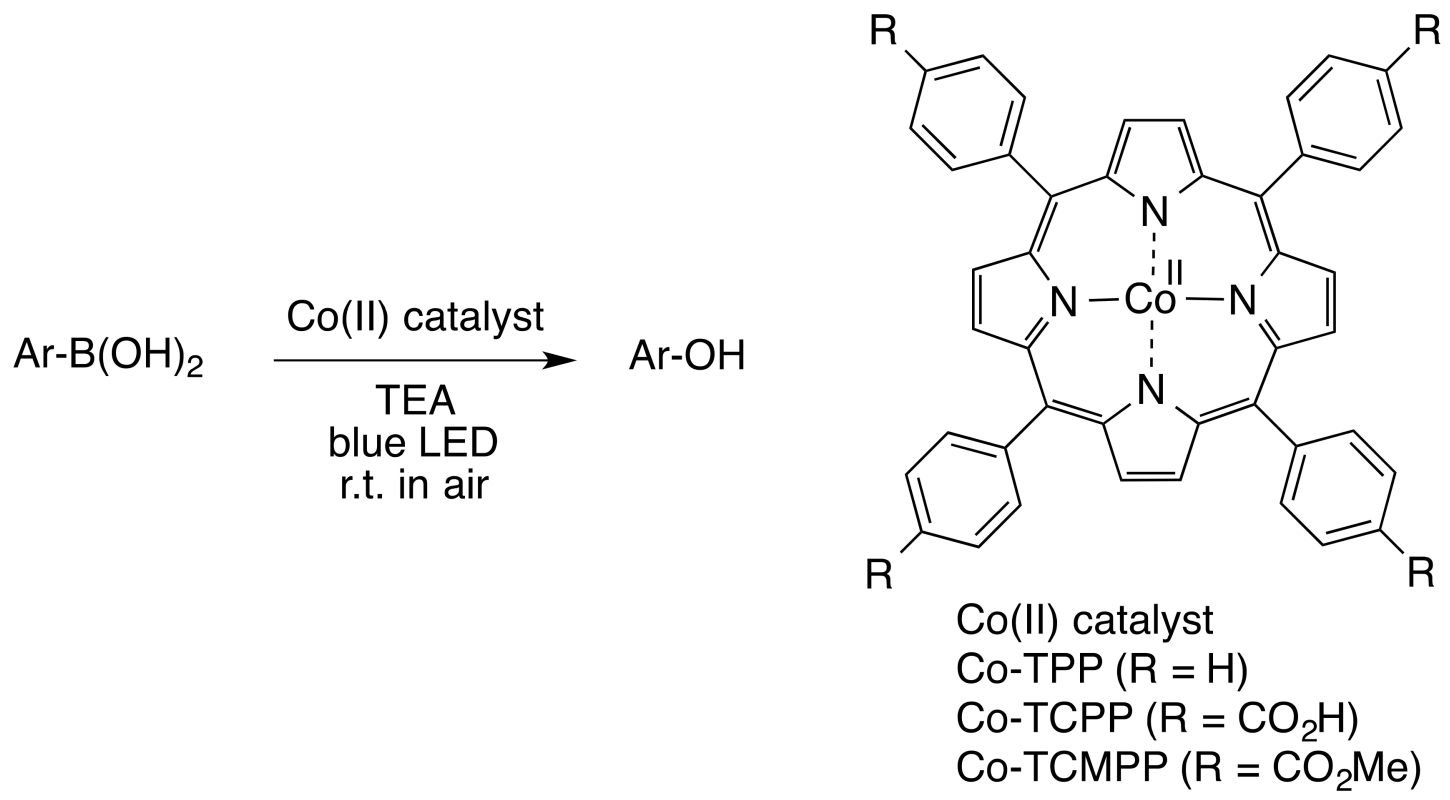

Scheme 1. Hydroxylation of arylboronic acid catalyzed by Co(II)-porphyrins.

\section{Results and Discussion}

The reaction proceeded through treatment of phenyl boronic acid in a basic aqueous solution at room temperature under irradiation of blue light $(523 \mathrm{~nm})$ and exposed to air (Figure 1). A range of catalysts, additives and solvents were used, and the reaction time and yield were measured. The results are shown in Table 1.

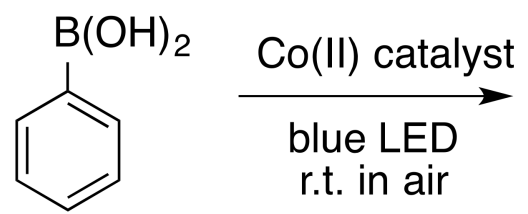<smiles>Oc1ccccc1</smiles>

$$
\begin{aligned}
& \text { Co(II) catalyst } \\
& \text { Co-TPP }(\mathrm{R}=\mathrm{H}) \\
& \text { Co-TCPP }\left(\mathrm{R}=\mathrm{CO}_{2} \mathrm{H}\right) \\
& \text { Co-TCMPP }\left(\mathrm{R}=\mathrm{CO}_{2} \mathrm{Me}\right)
\end{aligned}
$$

Figure 1. Hydroxylation of phenylboronic acid catalyzed by Co(II)-porphyrins.

Table 1. Co-catalyzed hydroxylation of phenylboronic acid under irradiation ${ }^{1}$.

\begin{tabular}{cccccc}
\hline Entry & Catalyst & Additives & Solvent & Time (h) & Yield (\%) \\
\hline 1 & none & none & $\mathrm{H}_{2} \mathrm{O}$ & 12 & 0 \\
2 & none & $\mathrm{H}_{2} \mathrm{O}_{2}$ & $\mathrm{CH}_{3} \mathrm{CN} / \mathrm{H}_{2} \mathrm{O}$ & 6 & 18 \\
3 & $\mathrm{Pd}(\mathrm{OAc})_{2}$ & TEA & $\mathrm{CH}_{3} \mathrm{CN} / \mathrm{H}_{2} \mathrm{O}$ & 12 & 0 \\
4 & $\mathrm{H}_{2} \mathrm{TPP}$ & TEA & $\mathrm{CH}_{3} \mathrm{CN} / \mathrm{H}_{2} \mathrm{O}$ & 12 & 0 \\
5 & $\mathrm{Co}-\mathrm{TPP}$ & TEA & $\mathrm{CH}_{3} \mathrm{CN} / \mathrm{H}_{2} \mathrm{O}$ & 12 & 40 \\
6 & Co-TCMPP & TEA & $\mathrm{CH}_{3} \mathrm{CN} / \mathrm{H}_{2} \mathrm{O}$ & 12 & 60 \\
7 & Co-TCPP & TEA & $\mathrm{CH}_{3} \mathrm{CN} / \mathrm{H}_{2} \mathrm{O}$ & 12 & 70 \\
8 & Co-TPP/PANI & TEA & pyridine & 6 & 0 \\
9 & Co-TPP/PANI & TEA & $\mathrm{DMF}$ & 6 & 0 \\
10 & $\mathrm{Co-TPP/PANI}$ & TEA & $\mathrm{CH}_{3} \mathrm{CN}$ & 6 & 0 \\
11 & Co-TPP/PANI & TEA & $\mathrm{H}_{2} \mathrm{O}$ & 6 & 42 \\
12 & Co-TCPP/PANI & TEA & $\mathrm{CH}_{3} \mathrm{CN} / \mathrm{H}_{2} \mathrm{O}$ & 6 & 90 \\
13 & Co-TCPP/Cts & TEA & $\mathrm{CH}_{3} \mathrm{CN} / \mathrm{H}_{2} \mathrm{O}$ & 6 & 88 \\
$14^{2}$ & Co-TCPP/PANI & TEA & $\mathrm{CH}_{3} \mathrm{CN} / \mathrm{H}_{2} \mathrm{O}$ & 6 & 0 \\
$15^{3}$ & Co-TCPP/PANI & TEA & $\mathrm{CH}_{3} \mathrm{CN} / \mathrm{H}_{2} \mathrm{O}$ & 6 & 0 \\
\hline
\end{tabular}

${ }^{1}$ Reaction conditions: phenylboronic acid $(1 \mathrm{mmol})$, TEA $(5.0 \mathrm{mmol})$, catalyst $(0.3 \mathrm{~mol} \%$ of Co-TCPP, $0.3 \mathrm{~mol} \%$ polyaniline) in $5 \mathrm{~mL} \mathrm{MeCN}: \mathrm{H}_{2} \mathrm{O}(4: 1)$ at $\mathrm{pH}=9$ using $\mathrm{NaOH}(0.1 \mathrm{~N})$, blue light $(523 \mathrm{~nm})$, in air, r.t. ${ }^{2}$ In the absence of blue light. ${ }^{3}$ Under $\mathrm{N}_{2}$ atmosphere. 
In the absence of a catalyst and additives, no reaction proceeded at all, and the substrate was recovered quantitatively (entry 1 , Table 1). It was revealed that phenyl boronic acid cannot be decomposed under blue-light irradiation conditions alone. Transition metal catalysts and triethylamine as a sacrificial reagent to promote the oxidation processes were then tested; $0.3 \mathrm{~mol} \%$ of $\mathrm{Co}$ (II)-porphyrin served as an effective catalytic system to provide phenol from phenyl boronic acid (entries 2-5, Table 1). Oxidative hydroxylation did not occur in the absence of porphyrin. Substituents on the porphyrin ligand of Co(II)-catalysts were greatly affected by blue-light irradiation in air (entries 5-7, Table 1). Carboxylic acid substituted porphyrin (Co-TCPP, $\mathrm{R}=\mathrm{CO}_{2} \mathrm{H}$ ) efficiently achieved the oxidation reaction and produced the best yield (entry 7, Table 1). No reaction occurred in the absence of TEA, as it is responsible for energy transfer from the activated $\mathrm{Co}$ (II)-porphyrin species as an electron donor to form a Co(I)-porphyrin species. This optimized result shows that the solubility of the catalyst influences the yield of oxidation reactions in the homogeneous catalytic system.

The oxidation reactions considered were expanded to include more eco-friendly systems. We investigated the reactions promoted by $\mathrm{Co}(\mathrm{II})$-porphyrin catalysts combined with a polymer as a sustainable solid phase method (entries $8-15$, Table 1). Polyaniline and chitosan immobilized to $\mathrm{Co}(\mathrm{II})$-porphyrin were employed as the practical photosensitizer. Modest yields of the desired product were obtained using water as the solvent (entry 11, Table 1). Almost no reaction proceeded using dry pyridine, dimethylformaldehyde (DMF) and $\mathrm{MeCN}$ without water. These results suggest that the hydroxyl group of water plays an important role in the hydroxylation processes [39]. The highest yield was obtained using Co(II)-porphyrin/polyaniline hydrochloride (Co(II)TCPP/PANI) as the solid phase catalyst under the standard conditions using a $\mathrm{MeCN}: \mathrm{H}_{2} \mathrm{O}$ solvent in a 4:1 ratio (entry 12, Table 1). Co(II)-porphyrin/chitosan complex (Co(II)TCPP/Cts) could also be used effectively to obtain the desired product (entry 13, Table 1). Although the hydroxylations of phenyl boronic acid proceeded efficiently using Co(II)TCPP/PANI and Co(II)TCPP/Cts in high yields, the isolation of the product for homogeneous $\mathrm{Co}(\mathrm{II}) \mathrm{TCPP} / \mathrm{Cts}$ complex was very difficult [40]. The heterogeneous system gave higher yield and easier isolation, so further studies were undertaken using the Co(II)TCPP/PANI catalytic system. A total of $0.2 \mathrm{~mol} \%$ of $\mathrm{Co}$ (II)-porphyrin catalyst provided the desired product in $30 \%$ yield under similar conditions, so that the concentration should be increased until the higher yield of 0.3 $\mathrm{mol} \%$ catalyst loading. Higher concentration of porphyrin in more than $0.3 \mathrm{~mol} \%$ would cause a decrease in the adsorption of other starting material on the polymer surface due to the aggregation of porphyrin. When the concentration of $\mathrm{Co}$ (II)-porphyrin catalyst increased as the aggregation form of porphyrin, it seemed to be less reactive than the monomeric form [41,42].

These collected results suggest that the photosensitizer, blue light and atmospheric air are essential for the reaction. No reaction proceeded under nitrogen atmosphere and in the natural light (in the absence of blue light) (entries 14 and 15, Table 1). As the porphyrins absorbed intensely in the Soret region (around $435 \mathrm{~nm}$ ) and partially in the Q region (around 500-600 nm), we carried out all hydroxylation reactions under blue LED light $(435-600 \mathrm{~nm})[43,44]$. While similar oxidation reactions from phenyl boronic acid to phenol have been reported elsewhere [45-47], the toxicity of hydrogen peroxide, longer reaction times (from $24 \mathrm{~h}$ to several days) and higher temperatures make them less-efficient reactions and less eco-friendly [48,49]. The protocol developed here using a Co(II)-porphyrin system showed higher yields within $6 \mathrm{~h}$ and mild reaction conditions (room temperature and under the atmosphere) and could be used as an environmentally friendly, reusable catalyst for oxidative hydroxylation transformations.

Boronic acids with other functional groups were examined under similar catalytic conditions; the results are shown in Table 2 (Figure 2). Monomethyl- and trimethyl-substituted phenylboronic acids gave the corresponding substituted phenols within 4-6 h and with yields above $90 \%$ (entries 2 and 3, Table 2). $p$-Bromophenyl boronic acid was tolerated to form the oxidized product, and the hydroxylation reaction proceeded without any observable debromination under blue-light irradiation. The 1-Naphthylboronic acid gave the desired 1-naphthol in high yield under $4 \mathrm{~h}$ at similar conditions (entry 5, Table 2). Thus, Co(II)TCPP supported on polyaniline served as a sufficient and suitable 
catalytic system to form the functionalized substituted phenols and naphthol in air without any oxidizing agents. The products were isolated and characterized by ${ }^{1} \mathrm{H} N M R,{ }^{13} \mathrm{C} N M R$, and mass spectrometry, and these data are reported in Supporting Information.

Table 2. Co-catalyzed oxidation of substituted phenyl boronic acids.

\begin{tabular}{cccc}
\hline Entry & Boronic Acid $\left(\mathbf{R}^{\mathbf{1}}, \mathbf{R}^{\mathbf{2}}, \mathbf{R}^{\mathbf{3}}\right)$ & Time (h) & Yield (\%) \\
\hline 1 & Phenyl boronic acid $\left(\mathrm{R}^{1}, \mathrm{R}^{2}, \mathrm{R}^{3}=\mathrm{H}\right)$ & 6 & 90 \\
2 & $p$-Methylphenyl boronic acid $\left(\mathrm{R}^{2}=\mathrm{Me}\right)$ & 4 & 96 \\
3 & 2,4,6-Trimethylphenyl boronic acid $\left(\mathrm{R}^{1}, \mathrm{R}^{2}, \mathrm{R}^{3}=\mathrm{Me}\right)$ & 6 & 92 \\
4 & $p$-Bromophenyl boronic acid $\left(\mathrm{R}^{2}=\mathrm{Br}\right)$ & 12 & 80 \\
5 & 1-Naphthylboronic acid & 4 & 95 \\
\hline
\end{tabular}

Reaction conditions: arylboronic acid $(1 \mathrm{mmol})$, TEA $(5.0 \mathrm{mmol})$, catalyst $(0.3 \mathrm{~mol} \%$ of Co-TCPP, $0.3 \mathrm{~mol} \%$ of polyaniline) in $5 \mathrm{~mL} \mathrm{MeCN}: \mathrm{H}_{2} \mathrm{O}(4: 1)$ at $\mathrm{pH}=9$ using $\mathrm{NaOH}(0.1 \mathrm{~N})$, Visible Light, in air, at room temperature.<smiles>[R2]c1cc([R])c(Br)c([18OH])c1</smiles>

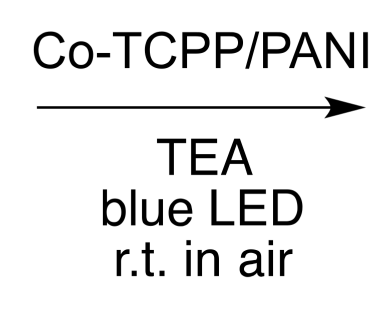<smiles>[R2]c1cc([R])c(O)c([125I])c1</smiles>

Figure 2. Hydroxylation of substituted arylboronic acids catalyzed by Co(II)TCPP/PANI.

Although it is premature to draw conclusions regarding the reaction mechanism at present, a plausible mechanism is presented in Scheme 2. The Co(II)-porphyrin catalyst is excited by irradiation of blue light at $523 \mathrm{~nm}$ and undergoes a single-electron transfer (SET) accompanied by the generation of an activated $\mathrm{Co}(\mathrm{II})$-porphyrin species. Energy transferred from the $\mathrm{Co}(\mathrm{II})$-porphyrin in its excited state species with triethylamine as an electron donor causes the formation of a Co(I)-porphyrin species, then accelerates the reduction of oxygen to give a superoxide radical anion $\left(\mathrm{O}_{2}{ }^{\circ-}\right)$ species. The oxidative hydroxylation of aryl boronic acid might proceed via the coupling reaction of boronic acid with the superoxide radical anion through photoredox processes in air. Subsequently, the formed superhydroxy anion combines with the boronic acids at the vacant $p$-orbital to afford the superhydroxy borate intermediate and accompanying reduction by triethylamine to the iminium cation, and Co(II)-porphyrin could then be regenerated [45]. The hydroxylation process would be completed by migratory insertion of the hydroxyl anion to form triaryl borate followed by hydrolysis to give rise to the corresponding phenol derivatives [46]. 


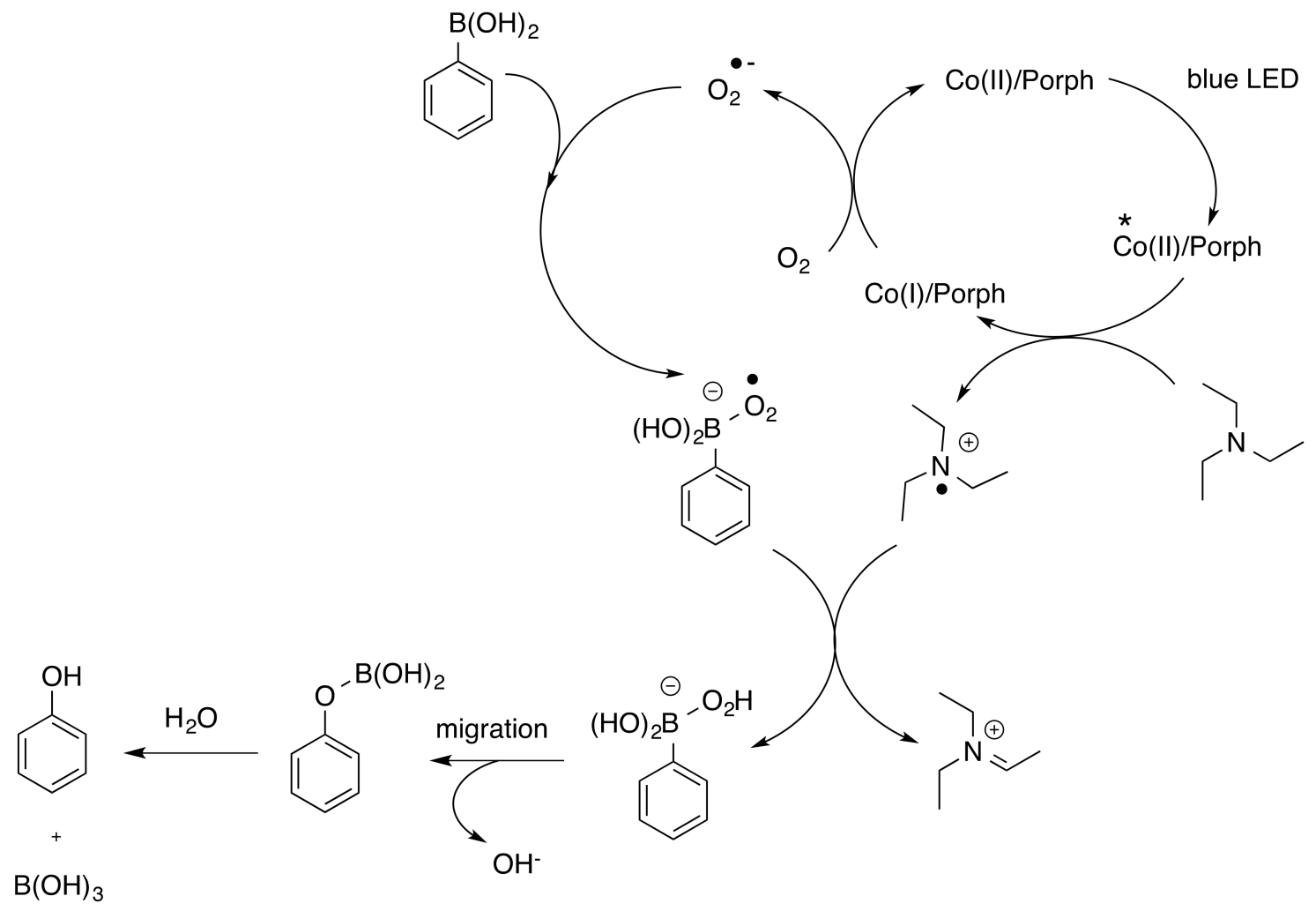

Scheme 2. Plausible reaction mechanism for oxidation of phenyl boronic acid under irradiation of blue LED.

\section{Materials and Methods}

\subsection{Preparation of Meso-Tetraphenylporphyrin $\mathrm{H}_{2}$ (TPP)}

Benzaldehyde ( $4 \mathrm{~mL}, 40 \mathrm{mmol}$ ) was added to $150 \mathrm{~mL}$ propionic acid and then heated to $80{ }^{\circ} \mathrm{C}$ in a three-neck round flask. Pyrrole $(2.8 \mathrm{~mL}, 40 \mathrm{mmol})$ was added to the mixture over a 15 -min period before the temperature was increased to $180{ }^{\circ} \mathrm{C}$. After $1 \mathrm{~h}$, the reaction mixture was cooled to room temperature and filtered. The solid residue was washed with hot water and methanol. After drying under reduced pressure, the desired product was obtained in $50 \%$ as a purple crystal.

\subsection{Preparation of 5,10,15,20-Tetrakis[4-(methoxycarbonyl)phenyl]porphyrin $\mathrm{H}_{2}$ (TMCPP)}

p-Methoxycarbonyl benzaldehyde $(1.312 \mathrm{~g}, 8 \mathrm{mmol})$ was added to $100 \mathrm{~mL}$ propionic acid and stirred at $80^{\circ} \mathrm{C}$ in a three-neck round flask. Pyrrole $(0.56 \mathrm{~mL}, 8 \mathrm{mmol})$ was added to the mixture over a 15 -min period before the temperature was increased to $140{ }^{\circ} \mathrm{C}$. After $1 \mathrm{~h}$, the reaction mixture was cooled to room temperature under the air atmosphere. The reaction solution was filtered and washed with hot water and methanol to remove adsorbed acid. Purple crystals were obtained in $40 \%$ after purification by thin-layer chromatography with silica gel-coated glass plates using methylene chloride as the eluent.

\subsection{Preparation of 5,10,15,20-Tetrakis(4-carboxyphenyl)porphyrin $\mathrm{H}_{2}$ (TCPP)}

$\mathrm{H}_{2}$ (TMCPP) (0.12 mmol) was dissolved in $5 \mathrm{~mL}$ trifluoroacetic acid, $2.5 \mathrm{~mL} \mathrm{HCl}(35 \%)$ was added to the solution and the mixture was stirred at $85^{\circ} \mathrm{C}$ for $36 \mathrm{~h}$. The reaction mixture was diluted with cold water to give a green precipitate that was then filtered and washed with water and $\mathrm{CH}_{2} \mathrm{Cl}_{2}$ three times to remove unreacted $\mathrm{H}_{2}$ (TMCPP). The green solid was dissolved in $10 \mathrm{~mL}$ pyridine, filtered, and evaporated after washing with water and $\mathrm{CH}_{2} \mathrm{Cl}_{2}$ to give an $80 \%$ yield of $\mathrm{H}_{2}$ (TCPP) as purple powder. 


\subsection{Metallation of Porphyrins}

$\mathrm{Co}(\mathrm{II}) \mathrm{TPP}, \mathrm{Co}(\mathrm{II}) \mathrm{TMCPP}$ and $\mathrm{Co}(\mathrm{II}) \mathrm{TCPP}$ were prepared by the reaction of $\mathrm{H}_{2}$ (TPP), $\mathrm{H}_{2}$ (TMCPP) and $\mathrm{H}_{2}$ (TCPP) (1 mmol) with $\mathrm{CoCl}_{2} \cdot 6 \mathrm{H}_{2} \mathrm{O}(6 \mathrm{mmol})$ in $150 \mathrm{~mL}$ dimethylformamide followed by refluxing for $6 \mathrm{~h}$ under a nitrogen atmosphere. After the solution was cooled to room temperature, the solvent was evaporated under vacuum. The residue was washed with water and dried under vacuum to give the corresponding $\mathrm{Co}(\mathrm{II})$-porphyrins.

\subsection{Preparation of Co(II)TCPP Immobilized on Chitosan (CTS)}

In a three-neck round flask, a mixture of CTS $(0.1 \mathrm{~g})$ and diluted acetic acid $(5 \mathrm{~mL})$ was stirred at room temperature for $15 \mathrm{~min}$. Then, $10 \mathrm{~mL}$ distilled water was added to form a colloidal solution. Next, $2.85 \mathrm{~mol} \cdot \mathrm{L}^{-1} \mathrm{NH}_{3} \cdot \mathrm{H}_{2} \mathrm{O}$ solution was added dropwise until the colloidal solution became neutral. Co-TCPP $(0.05 \mathrm{~g})$ was dissolved in ethanol $(100 \mathrm{~mL})$ and then slowly added to the reaction system. The solution was stirred for $24 \mathrm{~h}$, and the reaction was stopped and filtered. A saturated $\mathrm{NH}_{4} \mathrm{HCO}_{3}$ solution was then added to the obtained pale-yellow colloid and stirred for $2 \mathrm{~h}$. The mixture was filtered and dried under vacuum to obtain a Co-TCPP/p-CTS complex.

\subsection{Preparation of Polyaniline Emeraldine Hydrochloride}

Aniline hydrochloride $(2.29 \mathrm{~g}, 20 \mathrm{mmol})$ was dissolved in $50 \mathrm{~mL}$ distilled water. Following that, ammonium peroxydisulfate $(5.71 \mathrm{~g}, 25 \mathrm{mmol})$ was dissolved in distilled water $(50 \mathrm{~mL})$ and added dropwise to the aqueous solution of aniline hydrochloride at ambient temperature. After cooling for 1 $h$ in an ice bath, the radical initiator was added very slowly and the polymerization reaction was left for $24 \mathrm{~h}$ at ambient temperature. After $24 \mathrm{~h}$, the reaction mixture was filtered, and the precipitate was washed three times with aqueous $\mathrm{HCl}(0.2 \mathrm{M})$ and once with acetone. The green powder of polyaniline emeraldine hydrochloride was obtained after drying under atmospheric air [50-52].

\subsection{General Method for Hydroxylation Reaction}

\subsubsection{Hydroxylation Reaction Catalyzed by Co(II)TPP, Co(II)TMCPP, Co(II)TCPP}

A mixture of arylboronic acid ( $1 \mathrm{mmol}), 0.3 \mathrm{~mol} \%$ of catalyst in $5 \mathrm{~mL}$ of $\mathrm{MeCN}: \mathrm{H}_{2} \mathrm{O}(4: 1)$ and TEA $(0.64 \mathrm{~mL}, 5.0 \mathrm{mmol})$ was added to the reaction mixture, and the mixture was stirred at room temperature under blue light.

\subsubsection{Hydroxylation Reaction Catalysed by Co(II)TCPP Supported on Polyaniline}

A mixture of $(0.3 \mathrm{~mol} \%)$ of $\mathrm{Co}(\mathrm{II}) \mathrm{TCPP}$ and $(0.3 \mathrm{~mol} \%)$ of prepared polyaniline was stirred for 15 min in $5 \mathrm{~mL}$ of $\mathrm{MeCN}: \mathrm{H}_{2} \mathrm{O}$ (4:1) at $\mathrm{pH} 9$ using $\mathrm{NaOH}$ solution until complete adsorption of catalyst on the polyaniline surface. Arylboronic acid $(1 \mathrm{mmol})$ and TEA $(0.64 \mathrm{~mL}, 5.0 \mathrm{mmol})$ were added to the reaction mixture and the mixture was stirred at room temperature under blue light.

\section{Conclusions}

Co(II)TCPP immobilized on chitosan or polyaniline were used as photoredox catalytic species for the oxidative hydroxylation of aryl boronic acids in the presence of triethylamine under blue-light irradiation. The immobilized porphyrins had the highest catalytic activity compared with the basic Co(II)-porphyrin. We developed eco-friendly reactions for the hydroxylation of phenyl boronic acid that does not require oxidizing agents. These photoredox catalytic protocols in the absence of harmful oxidizing agents could serve as new oxidation methods. The immobilized porphyrins on polyaniline were more investigated because improving the stability by site isolation prevents porphyrin aggregation and intermolecular self-oxidation. Moreover, $\mathrm{Co}(\mathrm{II}) \mathrm{TCPP}$ immobilized on chitosan or polyaniline could increase its photocatalytic activities as well as the total turnover frequencies (TOFs). More detailed 
investigations into the reaction mechanisms and the practical use for the recycling solid catalysts are ongoing.

Supplementary Materials: The following are available online at http://www.mdpi.com/2073-4344/10/11/1262/s1. Experimental procedures and characterization $\left({ }^{1} \mathrm{H}\right.$ and ${ }^{13} \mathrm{C}$ NMR, MS, FTIR and fluorescence spectra) for all the catalysts and products are provided in the supporting information.

Author Contributions: Investigation, data curation, methodology, A.A.A.; conceptualization, writing-original draft preparation, supervision, M.K. All authors have read and agreed to the published version of the manuscript.

Funding: This work was supported by a Grant-in-Aid for Scientific Research (B) (JP18H01981) from JSPS and partly by a Grant-in-Aid for Scientific Research on Innovative Areas, "Precise Formation of a Catalyst Having a Specified Field for Use in Extremely Difficult Substrate Conversion Reactions" (18H04266) from MEXT. This work was also carried out by the research program of the Artificial Photosynthesis, Osaka City University.

Acknowledgments: We express our gratitude to G. Onodera for helpful discussion and critical comments. We are also thanking T. Fukuda for helpful discussion and critical comments.

Conflicts of Interest: The authors declare no conflict of interest.

\section{References}

1. Jeyakumar, K.; Chand, D.K. Selective oxidation of sulfides to sulfoxides and sulfones at room temperature using $\mathrm{H}_{2} \mathrm{O}_{2}$ and a Mo (VI) salt as catalyst. Tetrahedron Lett. 2006, 47, 4573-4576. [CrossRef]

2. Molloy, J.J.; Clohessy, T.A.; Irving, C.; Anderson, N.A.; Lloyd-Jones, G.C.; Watson, A.J.B. Chemoselective oxidation of aryl organoboron systems enabled by boronic acid-selective phase transfer. Chem. Sci. 2017, 8, 1551-1559. [CrossRef]

3. Yin, W.; Pan, X.; Leng, W.; Chen, J.; He, H. The highly efficient air oxidation of aryl and alkyl boronic acids by a microwave-assisted protocol under transition metal-free conditions. Green Chem. 2019, 21, 4614-4618. [CrossRef]

4. Zhu, C.; Wang, R.; Falck, J.R. Mild and rapid hydroxylation of aryl/heteroaryl boronic acids and boronate esters with N-oxides. Org. Lett. 2012, 14, 3494-3497. [CrossRef] [PubMed]

5. Goswami, A.; Chatterjee, N. Organic hypervalent iodine (III) catalyzed ipso-hydroxylation of aryl-and alkylboronic acids/esters. Tetrahedron Lett. 2015, 56, 1524-1527.

6. Romero, N.A.; Nicewicz, D.A. Organic photoredox catalysis. Chem. Rev. 2016, 116, 10075-10166. [CrossRef]

7. Huang, Z.; Gu, Y.; Liu, X.; Zhang, L.; Cheng, Z.; Zhu, X. Metal-Free Atom Transfer Radical Polymerization of Methyl Methacrylate with ppm Level of Organic Photocatalyst. Macromol. Rapid Commun. 2017, 38, 1600461. [CrossRef] [PubMed]

8. Pitre, S.P.; McTiernan, C.D.; Ismaili, H.; Scaiano, J.C. Mechanistic insights and kinetic analysis for the oxidative hydroxylation of arylboronic acids by visible light photoredox catalysis: A metal-free alternative. $J$. Am. Chem. Soc. 2013, 135, 13286-13289. [CrossRef] [PubMed]

9. Mori, T.; Ishii, C.; Kimura, M. Pd-Catalyzed Dehydrogenative Oxidation of Alcohols to Functionalized Molecules. Org. Process Res. Dev. 2019, 23, 1709-1717. [CrossRef]

10. Xie, H.-Y.; Han, L.-S.; Huang, S.; Lei, X.; Cheng, Y.; Zhao, W.; Sun, H.; Wen, X.; Xu, Q.-L. N-Substituted $3(10 \mathrm{H})$-Acridones as Visible-Light, Water-Soluble Photocatalysts: Aerobic Oxidative Hydroxylation of Arylboronic Acids. J. Org. Chem. 2017, 82, 5236-5241. [CrossRef]

11. Gualandi, A.; Savoini, A.; Saporetti, R.; Franchi, P.; Lucarini, M.; Cozzi, P.G. A facile hydroxylation of arylboronic acids mediated by sodium ascorbate. Org. Chem. Front. 2018, 5, 1573-1578. [CrossRef]

12. Silveira-Dorta, G.; Monzón, D.M.; Crisóstomo, F.P.; Martín, T.; Martín, V.S.; Carrillo, R. Oxidation with air by ascorbate-driven quinone redox cycling. Chem. Commun. 2015, 51, 7027-7030. [CrossRef] [PubMed]

13. Kotoučová, H.; Strnadová, I.; Kovandová, M.; Chudoba, J.; Dvořáková, H.; Cibulka, R. Biomimetic aerobic oxidative hydroxylation of arylboronic acids to phenols catalysed by a flavin derivative. Org. Biomol. Chem. 2014, 12, 2137-2142. [CrossRef]

14. Zou, Y.; Chen, J.; Liu, X.; Lu, L.; Davis, R.L.; Jørgensen, K.A.; Xiao, W. Highly efficient aerobic oxidative hydroxylation of arylboronic acids: Photoredox catalysis using visible light. Angew. Chem. Int. Ed. 2012, 51, 784-788. [CrossRef] 
15. Castro-Godoy, W.D.; Schmidt, L.C.; Argüello, J.E. A Green Alternative for the Conversion of Arylboronic Acids/Esters into Phenols Promoted by a Reducing Agent, Sodium Sulfite. Eur. J. Org. Chem. 2019, 2019, 3035-3039. [CrossRef]

16. Likhitwitayawuid, K.; Sritularak, B.; Benchanak, K.; Lipipun, V.; Mathew, J.; Schinazi, R.F. Phenolics with antiviral activity from Millettia erythrocalyx and Artocarpus lakoocha. Nat. Prod. Res. 2005, 19, 177-182. [CrossRef] [PubMed]

17. Owen, R.W.; Giacosa, A.; Hull, W.E.; Haubner, R.; Spiegelhalder, B.; Bartsch, H. The antioxidant/anticancer potential of phenolic compounds isolated from olive oil. Eur. J. Cancer 2000, 36, 1235-1247. [CrossRef]

18. Mulakayala, N.; Kumar, K.M.; Rapolu, R.K.; Kandagatla, B.; Rao, P.; Oruganti, S.; Pal, M. Catalysis by Amberlite IR-120 resin: A rapid and green method for the synthesis of phenols from arylboronic acids under metal, ligand, and base-free conditions. Tetrahedron Lett. 2012, 53, 6004-6007. [CrossRef]

19. Kim, H.-S.; Joo, S.-R.; Shin, U.S.; Kim, S.-H. Recyclable CNT-chitosan nanohybrid film utilized in copper-catalyzed aerobic ipso-hydroxylation of arylboronic acids in aqueous media. Tetrahedron Lett. 2018, 59, 4597-4601. [CrossRef]

20. Xu, J.; Wang, X.; Shao, C.; Su, D.; Cheng, G.; Hu, Y. Highly efficient synthesis of phenols by copper-catalyzed oxidative hydroxylation of arylboronic acids at room temperature in water. Org. Lett. 2010, 12, $1964-1967$. [CrossRef]

21. Schwarz, F.P.; Gouterman, M.; Muljiani, Z.; Dolphin, D.H. Energy transfer between covalently linked metal porphyrins. Bioinorg. Chem. 1972, 2, 1-32. [CrossRef]

22. Hong, Y.H.; Han, J.W.; Jung, J.; Nakagawa, T.; Lee, Y.-M.; Nam, W.; Fukuzumi, S. Photocatalytic Oxygenation Reactions with a Cobalt Porphyrin Complex Using Water as an Oxygen Source and Dioxygen as an Oxidant. J. Am. Chem. Soc. 2019, 141, 9155-9159. [CrossRef] [PubMed]

23. Wang, R.; Gao, B.; Jiao, W. A novel method for immobilization of Co tetraphenylporphyrins on $\mathrm{P}$ (4VP-co-St) $/ \mathrm{SiO}_{2}$ : Efficient catalysts for aerobic oxidation of ethylbenzenes. Appl. Surf. Sci. 2009, 255, 4109-4113. [CrossRef]

24. Shen, D.-H.; Ji, L.-T.; Liu, Z.-G.; Sheng, W.-B.; Guo, C.-C. Ethylbenzene oxidation over hybrid metalloporphyrin@ silica nanocomposite microspheres. J. Mol. Catal. A-Chem. 2013, 379, 15-20.

25. e Silva, R.C.; da Silva, L.O.; de Andrade Bartolomeu, A.; Brocksom, T.J.; de Oliveira, K.T. Recent applications of porphyrins as photocatalysts in organic synthesis: Batch and continuous flow approaches. Beilstein J. Org. Chem. 2020, 16, 917-955. [CrossRef]

26. Guo, C.-C.; Liu, Q.; Wang, X.-T.; Hu, H.-Y. Selective liquid phase oxidation of toluene with air. Appl. Catal. A Gen. 2005, 282, 55-59. [CrossRef]

27. Kumar, S.; Silva, J.D.A.E.; Wani, M.Y.; Gil, J.C.; Sobral, A.J. Carbon dioxide capture and conversion by an environmentally friendly chitosan based meso-tetrakis (4-sulfonatophenyl) porphyrin. Carbohydr. Polym. 2017, 175, 575-583. [CrossRef]

28. Haber, J.; Kłosowski, M.; Połtowicz, J. Co-oxidation of styrene and iso-butyraldehyde in the presence of polyaniline-supported metalloporphyrins. J. Mol. Catal. A Chem. 2003, 201, 167-178. [CrossRef]

29. Li, Z.; Zhou, X.; Shi, J.; Zou, X.; Huang, X.; Tahir, H.E. Preparation of conducting polyaniline/protoporphyrin composites and their application for sensing VOCs. Food Chem. 2019, 276, 291-297. [CrossRef]

30. Gottam, R.; Srinivasan, P.; La, D.D.; Bhosale, S.V. Improving the photocatalytic activity of polyaniline and a porphyrin via oxidation to obtain a salt and a charge-transfer complex. New J. Chem. 2017, 41, 14595-14601. [CrossRef]

31. Zhou, Q.; Li, C.M.; Li, J.; Lu, J. Electrocatalysis of template-electrosynthesized cobalt- porphyrin/polyaniline nanocomposite for oxygen reduction. J. Phys. Chem. C 2008, 112, 18578-18583. [CrossRef]

32. Huang, G.; Yuan, R.X.; Peng, Y.; Chen, X.F.; Zhao, S.K.; Wei, S.J.; Guo, W.X.; Chen, X. Oxygen oxidation of ethylbenzene over manganese porphyrin is promoted by the axial nitrogen coordination in powdered chitosan. RSC Adv. 2016, 6, 48571-48579. [CrossRef]

33. Mo, L.-Q.; Huang, X.-F.; Wang, G.-C.; Huang, G.; Liu, P. Full use of factors promoting catalytic performance of chitosan supported manganese porphyrin. Sci. Rep. 2020, 10, 1-14. [CrossRef] [PubMed]

34. Kowalski, G.; Pielichowski, J.; Grzesik, M. Characteristics of polyaniline cobalt supported catalysts for epoxidation reactions. Sci. World J. 2014, 2014, 1-9. [CrossRef] [PubMed] 
35. Elkhalafy, S.H.; Hassanein, M.T.; Abd-Elal, M.F.; Atia, A.A. Oxidation of azo dye Orange II with hydrogen peroxide catalyzed by 5, 10, 15, 20-tetrakis [4-(diethylmethylammonio) phenyl] porphyrinato-cobalt (II) tetraiodide in aqueous solution. J. Saudi Chem. Soc. 2020, 24, 520-526. [CrossRef]

36. Prier, C.K.; Rankic, D.A.; MacMillan, D.W.C. Visible light photoredox catalysis with transition metal complexes: Applications in organic synthesis. Chem. Rev. 2013, 113, 5322-5363. [CrossRef] [PubMed]

37. Ritleng, V.; Sirlin, C.; Pfeffer, M. Ru-, Rh-, and Pd-Catalyzed C-C Bond Formation Involving C-H Activation and Addition on Unsaturated Substrates: Reactions and Mechanistic Aspects. Chem. Rev. 2002, 102, 1731-1770. [CrossRef] [PubMed]

38. Sheldon, R.A. Atom efficiency and catalysis in organic synthesis. Pure Appl. Chem. 2000, 72, $1233-1246$. [CrossRef]

39. Serra, V.V.; Andrade, S.M.; Neves, M.G.; Cavaleiro, J.A.S.; Costa, S.M.B. J-aggregate formation in bis-(4-carboxyphenyl) porphyrins in water: $\mathrm{pH}$ and counterion dependence. New J. Chem. 2010, 34, 2757-2765. [CrossRef]

40. Ajit, S.; Palaniappan, S.; Kumar, P.U.; Madhusudhanachary, P. One-pot direct synthesis of fluorescent polyaniline-porphyrin macrospheres from porphyrin. J. Polym. Sci. Part A Polym. Chem. 2012, 50, 884-889. [CrossRef]

41. Toyao, T.; Ueno, N.; Miyahara, K.; Matsui, Y.; Kim, T.-H.; Horiuchi, Y.; Ikeda, H.; Matsuoka, M. Visible-light, photoredox catalyzed, oxidative hydroxylation of arylboronic acids using a metal-organic framework containing tetrakis (carboxyphenyl) porphyrin groups. Chem. Commun. 2015, 51, 16103-16106. [CrossRef]

42. Maiti, N.C.; Mazumdar, S.; Periasamy, N. J-and H-aggregates of porphyrin- surfactant complexes: Time-resolved fluorescence and other spectroscopic studies. J. Phys. Chem. B 1998, 102, 1528-1538. [CrossRef]

43. Abraham, B.; Nieto-Pescador, J.; Gundlach, L. Ultrafast relaxation dynamics of photoexcited zinc-porphyrin: Electronic-vibrational coupling. J. Phys. Chem. Lett. 2016, 7, 3151-3156. [CrossRef] [PubMed]

44. Shanmugam, S.; Xu, J.; Boyer, C. Exploiting metalloporphyrins for selective living radical polymerization tunable over visible wavelengths. J. Am. Chem. Soc. 2015, 137, 9174-9185. [CrossRef]

45. Ishida, Y.; Shimada, T.; Masui, D.; Tachibana, H.; Inoue, H.; Takagi, S. Efficient Excited Energy Transfer Reaction in Clay/Porphyrin Complex toward an Artificial Light-Harvesting System. J. Am. Chem. Soc. 2011, 133, 14280-14286. [CrossRef] [PubMed]

46. Akins, D.L.; Zhu, H.-R.; Guo, C. Aggregation of Tetraaryl-Substituted Porphyrins in Homogeneous Solution. J. Phys. Chem. 1996, 100, 5420-5425. [CrossRef]

47. Luo, D.; Huang, Y.; Hong, X.; Chen, D.; Li, G.; Huang, X.; Gao, W.; Liu, M.; Zhou, Y.; Wu, H. Phthalocyanine Zinc-catalyzed Hydroxylation of Aryl Boronic Acids under Visible Light. Adv. Synth. Catal. 2019, 361, 961-964. [CrossRef]

48. Shin, E.-J.; Joo, S.-R.; Kim, S.-H. Cooperation of biopolymer chitosan with hydrogen peroxide for ipso-hydroxylation of arylboronic acids under green conditions. Tetrahedron Lett. 2019, 60, 1509-1513. [CrossRef]

49. Jiang, H.; Lykke, L.; Pedersen, S.U.; Xiao, W.-J.; Jørgensen, K.A. A practical electromediated ipso-hydroxylation of aryl and alkyl boronic acids under an air atmosphere. Chem. Commun. 2012, 48, 7203-7205. [CrossRef]

50. Stejskal, J.; Gilbert, R.G. Polyaniline. Preparation of a conducting polymer (IUPAC technical report). Pure Appl. Chem. 2002, 74, 857-867. [CrossRef]

51. MacDiarmid, A.G.; Epstein, A.J. Polyaniline: Synthesis, Chemistry and Processing; Pennsylvania Univ. Philadelphia Dept. of Chemistry: Philadelphia, PA, USA, 1992.

52. Abu-Thabit, N.Y. Chemical oxidative polymerization of polyaniline: A practical approach for preparation of smart conductive textiles. J. Chem. Educ. 2016, 93, 1606-1611. [CrossRef]

Publisher's Note: MDPI stays neutral with regard to jurisdictional claims in published maps and institutional affiliations. 